International Journal of Biology, Pharmacy and Allied Seiences (IJBPAS) 'A Bridge Betuen Caboratory and Qnendo'

WwW.ijbpas.com

\title{
HYPERTENSION IN COMPLETELY EDENTULOUS PATIENTS- AN INSTITUTIONAL BASED STUDY
}

\section{SURESH $M^{1}$, RAKSHAGAN ${ }^{2 *}$ AND NIVETHIGAA $B^{3}$}

1: Saveetha Dental College and Hospitals, Saveetha Institute of Medical and Technical Sciences, Saveetha University, Chennai, India

2: Senior Lecturer, Department of Prosthodontics, Saveetha Dental College, Saveetha Institute of Medical and Technical Sciences, Saveetha University, Chennai, India

3: Senior Lecturer, Department of Orthodontics, Saveetha Dental College, Saveetha Institute of

Medical and Technical Sciences, Saveetha University, Chennai, India

*Corresponding Author: E Mail: Dr. Rakshagan: rakshagan.sdc@saveetha.com

Received $20^{\text {th }}$ March 2021; Revised 26 ${ }^{\text {th }}$ April. 2021; Accepted $24^{\text {th }}$ May 2021; Available online $1^{\text {st }}$ Aug. 2021

https://doi.org/10.31032/IJBPAS/2021/10.8.1100

\section{ABSTRACT}

Hypertension is a chronic illness affecting over a billion people worldwide. The high prevalence of the disease among the general population is concerning and must be considered when treating dental patients. The lack of symptoms until more serious problems occur makes the disease deadly. Dental practitioners play a major role in prevention of hypertension by evaluating preoperative blood pressure readings, performing risk assessments, and knowing when to consider medical consultation of a hypertensive patient in a dental setting. Determine the prevalence of hypertension among completely edentulous patients visiting Saveetha Dental College. Case records were of the patients visiting Saveetha Dental College between June 2019 to March 2020 were reviewed .This university setting study involved 354 completely edentulous patients .Data was tabulated with parameters of age, gender, medical history of hypertension and other systemic diseases. Data was imported to SPSS for statistical analysis .Descriptive statistics and chi square test was done. $85 \%$ of the population had hypertension. There was a higher 
predilection in males when compared to females. The most commonly affected age group was 60-75 years. Hypertension is associated with edentulism with $8.5 \%$ prevalence. Males are more affected and 60-75 years age group is more prevalent in this study. Further extensive research can be done with a larger population and geographical area.

Keywords: Complete denture; Edentulous; Gender; Hypertension; Prevalence

\section{INTRODUCTION}

Loss of teeth is mainly attributed to dental caries and periodontal diseases. All Factors leading to tooth extraction are not however dental in origin. Edentulousness and the number of remaining teeth are associated with Systemic diseases. Edentulism is defined as the loss of all permanent teeth and is the treatment outcome of a multifactorial process involving biologic process (dental caries, periodontal disease, trauma and others) as well as non-biologic factors related to dental procedures (access to care, patient preferences). The prevalence of tooth loss has been studied to a certain extent in western countries and a few such studies have been carried out in India [1].

Hypertension also known as the "silent killer, is one of the leading risk factors for cardiovascular disease mortality. The disease is defined as systolic blood pressure (SBP) of $140 \mathrm{mmHg}$ or diastolic blood pressure (DBP) $\geq 90 \mathrm{mmHg}$, or any persons being currently prescribed antihypertensive medicine for the purpose of managing hypertension. In addition, hypertension is defined as blood pressure readings elevated on at least two occasions with or without provocation $[2,3]$. The distribution of complete edentulism between developed and less developed countries is associated with an interrelationship between cultural, individual and socioeconomic factors and health. Edentulism is shown to increase with age, with females having higher rates of edentulism than males. It is estimated that around $17.6 \%$ of patients with hypertension globally live in India, which suggests an expected large increase in cardiovascular diseases burden [4-6] in the near future. BP control can avert almost a third of all cardiovascular-related mortality.

Tooth loss might lead to dietary pattern change, resulting in an increased risk of hypertension because the change of dietary pattern may be associated with hypertension [7, 8]. Systolic and diastolic blood pressure are important predictors for cardiovascular disease and stroke in the United States and Europe as well as in eastern Asia [9-12]. To appropriately manage their patients care, 
dentists and members of the dental team must be knowledgeable about hy- pertension, particularly its detection and treatment. Measurement of blood pressure and review of all medications, including herbal remedies and other over the counter medications, should be an integral part of the examination procedure. Dentists are encouraged to help the medical profession identify people who have elevated blood pressure so that these patients can be treated appropriately $[13,14]$. The care of patients with undetected or poorly controlled hypertension requires consultation with the patient's physician. Also, a significant number of antihypertensive medications have undesired oral side effects that require assessment and potential intervention by dentists. Patients with hypertension are at an increased risk of developing adverse effects in a dental office. Therefore, measuring BP should be done in the dental office to every patient, during each visit. In patients suffering from chronic systemic diseases, BP measurement will be carried out during more complicated dental interventions [15-17]. Routine measurement of BP reduces the risk of cardiovascular events and complications during dental treatment, especially when conscious sedation or general anesthesia is required. BP monitoring is vital for emergency treatment of patients who have side effects. Routine monitoring of patients with known hypertension allows the dentist to determine if $\mathrm{BP}$ is adequately controlled $[\mathbf{1 5}, \mathbf{1 8}]$.

This study was done in order to fulfill any shortcomings and helps in the assessment and understanding of different treatment modalities for a completely edentulous patient with hypertension. There is a continuous rise in the number of hypertensive individuals and the fact that the dental setting is viewed as a stressful environment for some individuals.

The combination of high blood pressure and a stressful environment may have harmful, even fatal consequences for patients, therefore this research aims at creating awareness about management of a hypertensive patient who is completely edentulous.

\section{MATERIALS AND METHODS}

This a retrospective study done under a university setting. The study was approved by the institutional ethics board. Two reviewers are involved in the study. The study was commenced after approval from the scientific review board, and the ethical clearance was obtained from the ethical committee of the University with the following ethical approval number- 


\section{SDC/SIHEC/2020/DIASDATA/0619-0320."}

The case records were taken from patients who had visited Saveetha Dental College from June 2019 to April 2020. Total number of sample size includes 354 patients. The case sheets were verified. To minimise the sampling bias, we included all the data available and there was no sorting of data done.

Internal validity of the study included all patients who had a complete denture .The external validity of the study is the epidemiological preference. We reviewed patient records and analysed the data of 354 patients between June 2019 to March 2020.The data of patients who were completely edentulous was reviewed and the data was tabulated. Data was verified by one external reviewer. The data was imported to SPSS and the variables were verified. Percentage and frequency were employed in the analysis to detect a significance between age, gender and a diagnosis of hypertension with other systemic disease.

Chi-square test was done on the data obtained using SPSS software by IBM. Hypertension, complete edentulousness was considered as dependent variables. Gender, Age group, Ethnicity was considered as independent variables. Correlation and association analysis was done.

\section{RESULTS AND DISCUSSION}

Out of a total of 351 completely edentulous patients. There were a total of 150 females and 204 males that took part in this study depicted in [Figure 1]. The patients were divided into different groups based on their age [Figure 2]. Majority of patients belonged to the $60-75$ years age group (54.2\%). They were also the group which had the most number of hypertensive patients [Figure 3].

[Figure 5] depicted the prevalence of hypertension in the overall population. There was also a higher predilection in males when compared to females [Figure 4]. In this study we observed that hypertension was prevalent in $8.5 \%$ of the population. Males had a higher predilection than females. People in the age group of 60-75 years had a higher predilection for hypertension.

Several studies have demonstrated that men use health care services at a much lower rate than women $[19,20]$, particularly at younger ages [21, 22]. Men are much more likely to be hypertensive than women, even after controlling for BMI, smoking, and physical activity, coupled with the fact that they are less likely to be aware of their underlying hypertension. In this study, age appears as one of the factors directly related to increased blood pressure. This is because of the fact that those who are elderly often present co- 
morbidities, this indicates that the sum of two factors such as age and high blood pressure is one of the most important medical risk factors in patients who are undergoing dental treatment .Another study states that as of 5560 years of age, an increased prevalence of HBP has been observed, which exceeds $65 \%$ in those older than $60-65$ years $[\mathbf{2 3}, \mathbf{2 4}]$. Of the hypertensive patients identified in this study, $(62.2 \%)$ were over the age of 50 years old

Some authors even suggest that dentists should be involved in the screening for HBP among younger patients, where the development of this disease is unusual [2527]. Hypertension is one of the most commonly diagnosed diseases and is related with increased cardiovascular risk and mortality. Many patients with hypertension have uncontrolled disease. The dentist has a crucial role in screening undiagnosed and undertreated hypertension, which leads to improved monitoring and treatment. It is generally recommended that emergency dental procedures be avoided in patients with a blood pressure of greater than $180 / 110 \mathrm{mmHg}$. Because of the high prevalence of disease and medication use for hypertension, dentists should be fully aware of the oral side effects of antihypertensive medications. Also, dentists should consider management of drug-drug interactions of antihypertensives with medications commonly used during dental visits [28, 29]. There is currently a lack of need among dental practitioners to routinely measure BP or to offer health and lifestyle advice to patients with regard to vascular risk factors. Many practitioners do not feel that this is a role that dentists should undertake and it may provoke hostility from patients who are not used to receiving this type of advice from their dentist [30, 31].

Only few people who are aware of the risk of hypertension may realize that they are walking around with this disease undiagnosed. Therefore, the role of dentists in detecting undiagnosed hypertension is crucial and should be emphasized in our specialty as a standard of care. Doing so will hopefully help to decrease the risk of death from this silent killer disease worldwide and prevent the development of life-threatening complications such as strokes or cardiovascular diseases during or after dental treatment [32-34].

Dentists should further be aware of the importance of anxiety control of their (medicated and unmedicated) hypertensive patients. Anxiety and psychosocial stressors have been linked to elevated blood pressure in susceptible patients. Practitioners may find 
it beneficial to premedicate with an anxiolytic agent the evening before the morning of a dental appointment when treating the anxious, hypertensive population. The management of the hypertensive patient, particularly within a dental setting, is a welldiscussed topic. Information about hypertensive patients is often published. It is important to implement these changes to maintain the quality of care while treating patients. A dental provider should have complete knowledge of the disease, be up to date with current therapeutic options, and have the ability to educate and provide health care for patients. The management of these patients is mainly based on one's judgment as a practitioner. Before providing care to these patients, the practitioner should be able to assess the patients health status and make proper decisions. Most importantly, medical advice should be considered. The health of the patient should always come first.

Following these routines might help in proper management of a hypertensive patients.

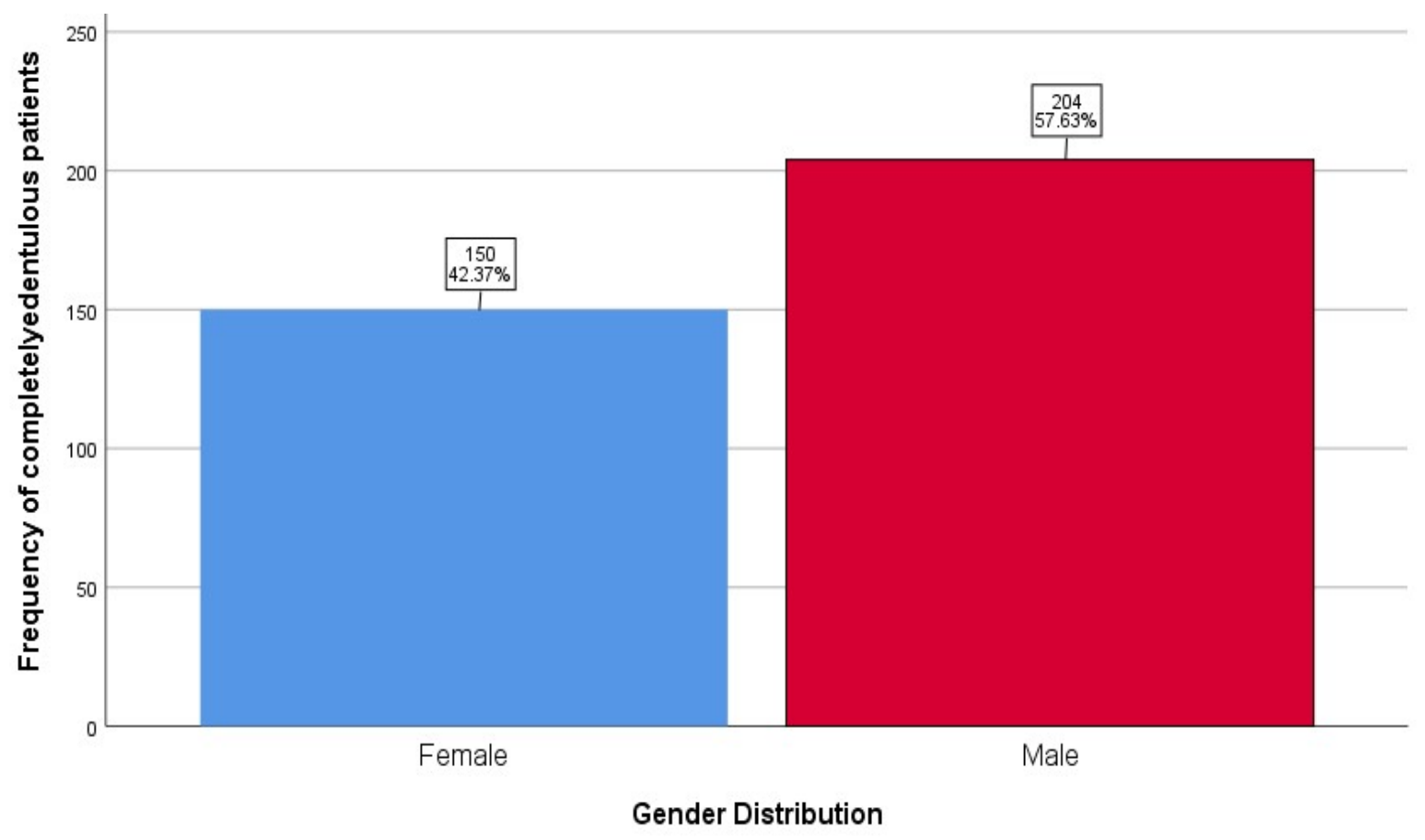

Figure 1: Bar graph represents the gender distribution of patients who are completely edentulous. $X$ axis represents the gender distribution. $Y$ axis represents the percentage of patients who were completely edentulous. The population consisted of females- $42.4 \%$, male-57.6\% represented as blue and red graphs respectively. 


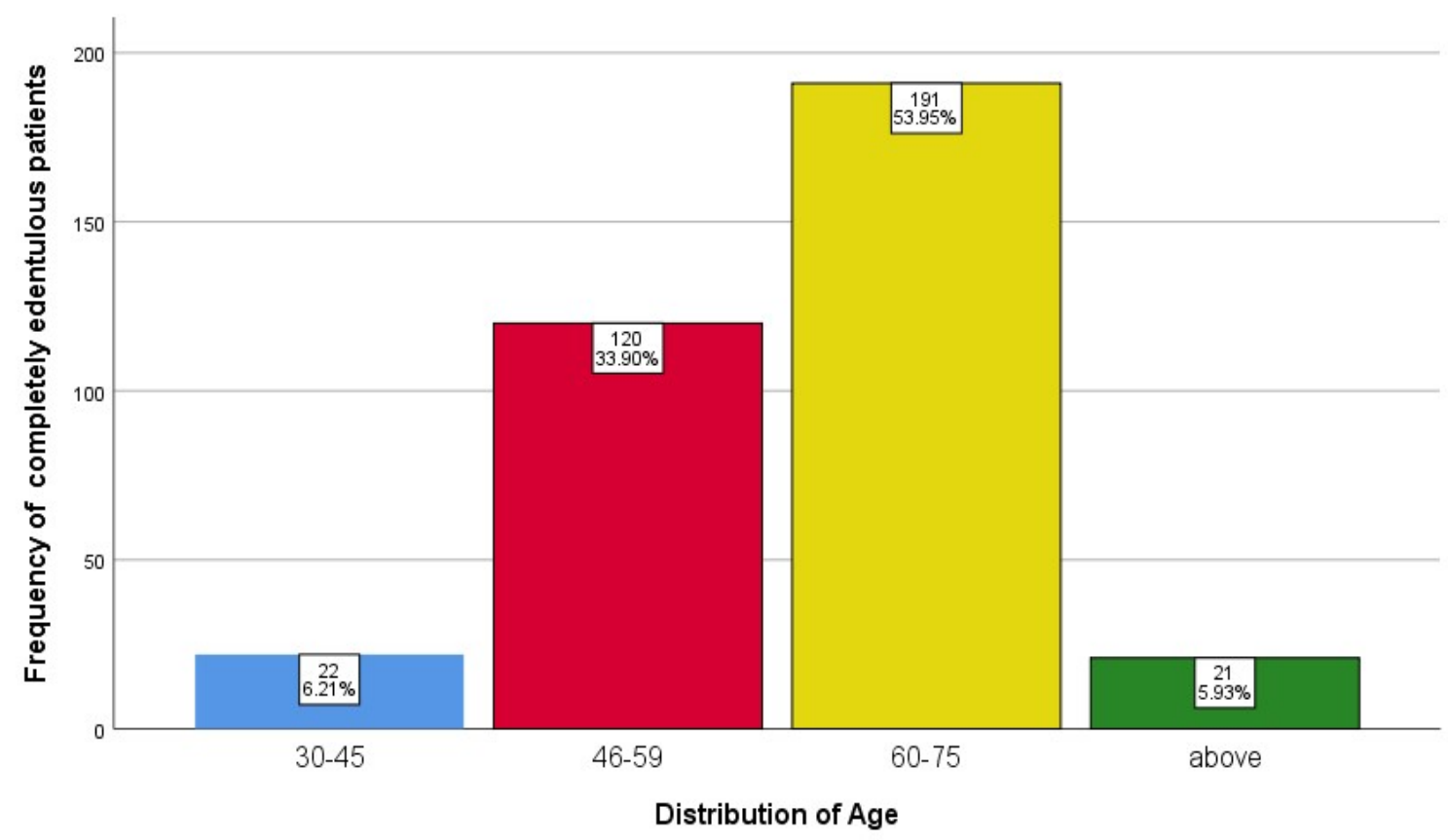

Figure 2: Bar chart depicts the age distribution. $\mathrm{X}$ axis represents the age groups and $\mathrm{Y}$ axis represents the Frequency of completely edentulous patients, $6.2 \%$ of the patients belong to the $30-45$ years age group (blue bar),33.9 \% belong to the 46-59 years(red bar), 53.9\% belonged to the 60-75 years age group (yellow bar) and $5.9 \%$ were above the age of 75 (green bar).

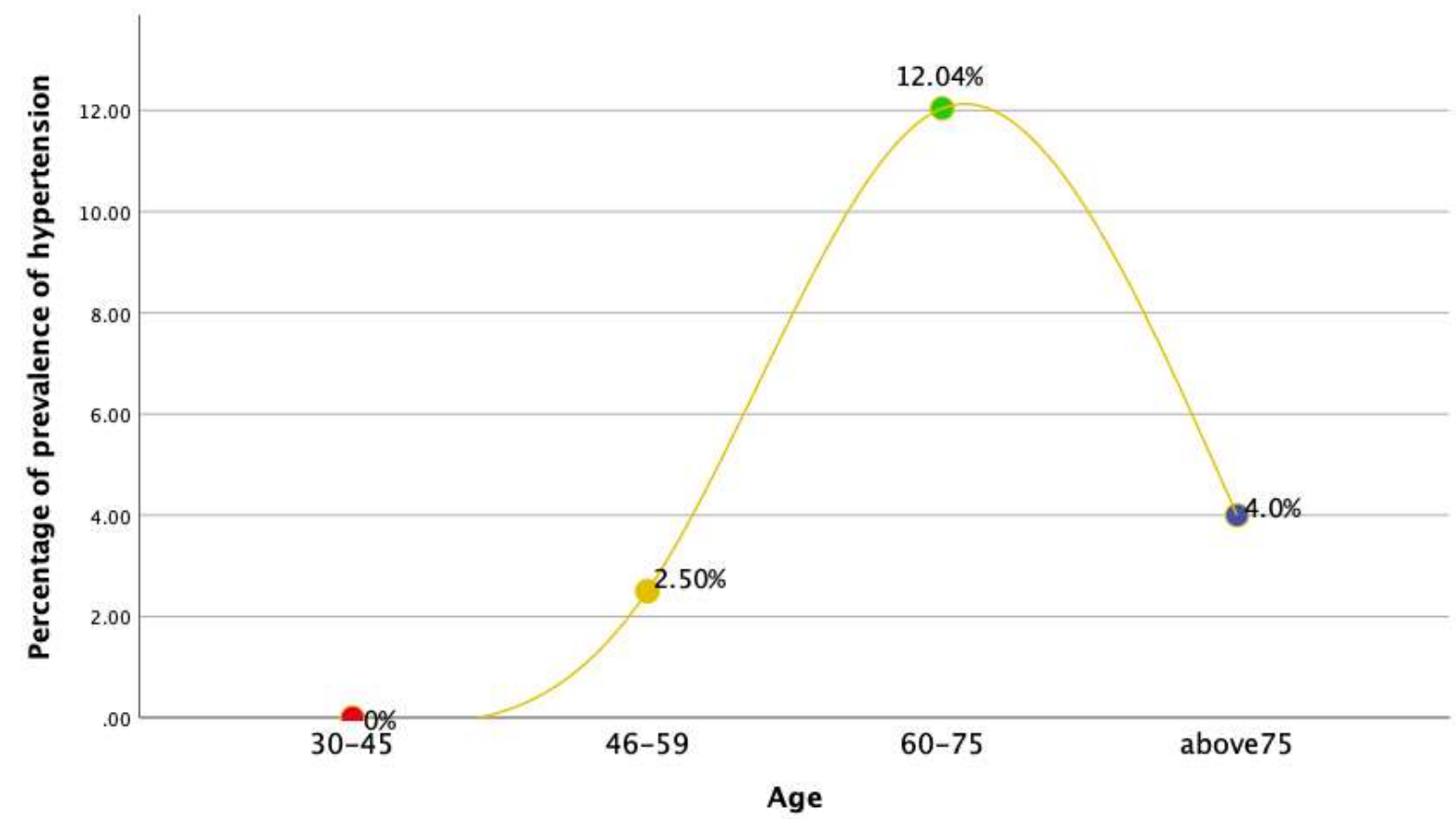

Figure 3: Scatter plot represents the comparison between the age and the percentage of patients who had hypertension. $X$ axis represents the age of the participants in years. $Y$ axis represents the percentage of patients who had hypertension. Majority of the people aged 60-75 years were more prevalent with Hypertension than the other age groups. However, there was no significant difference statistically. One sample t test - , $p$ value- $0.173(>0.05)$. 


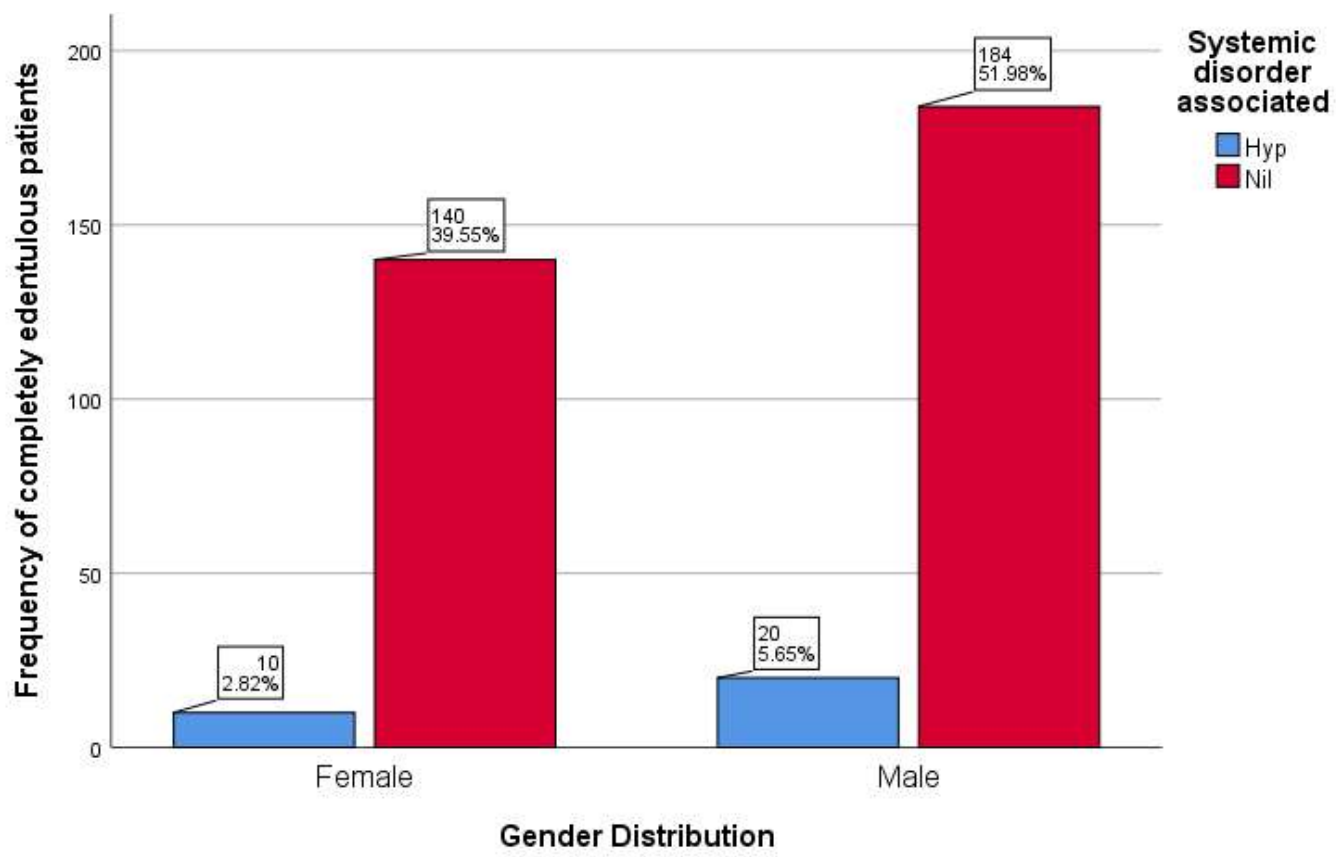

Figure 4: Bar chart depicts the association between gender and hypertension. $X$ axis represents the gender distribution. $Y$ axis represents the total number of patients. Majority of the completely edentulous males were highly prevalent with hypertension than the females. However there was no significant association between gender and hypertension. Pearson Chi Square value $-1.097, p$ value- $0.295 p$ value $>0.05$ statistically insignificant.

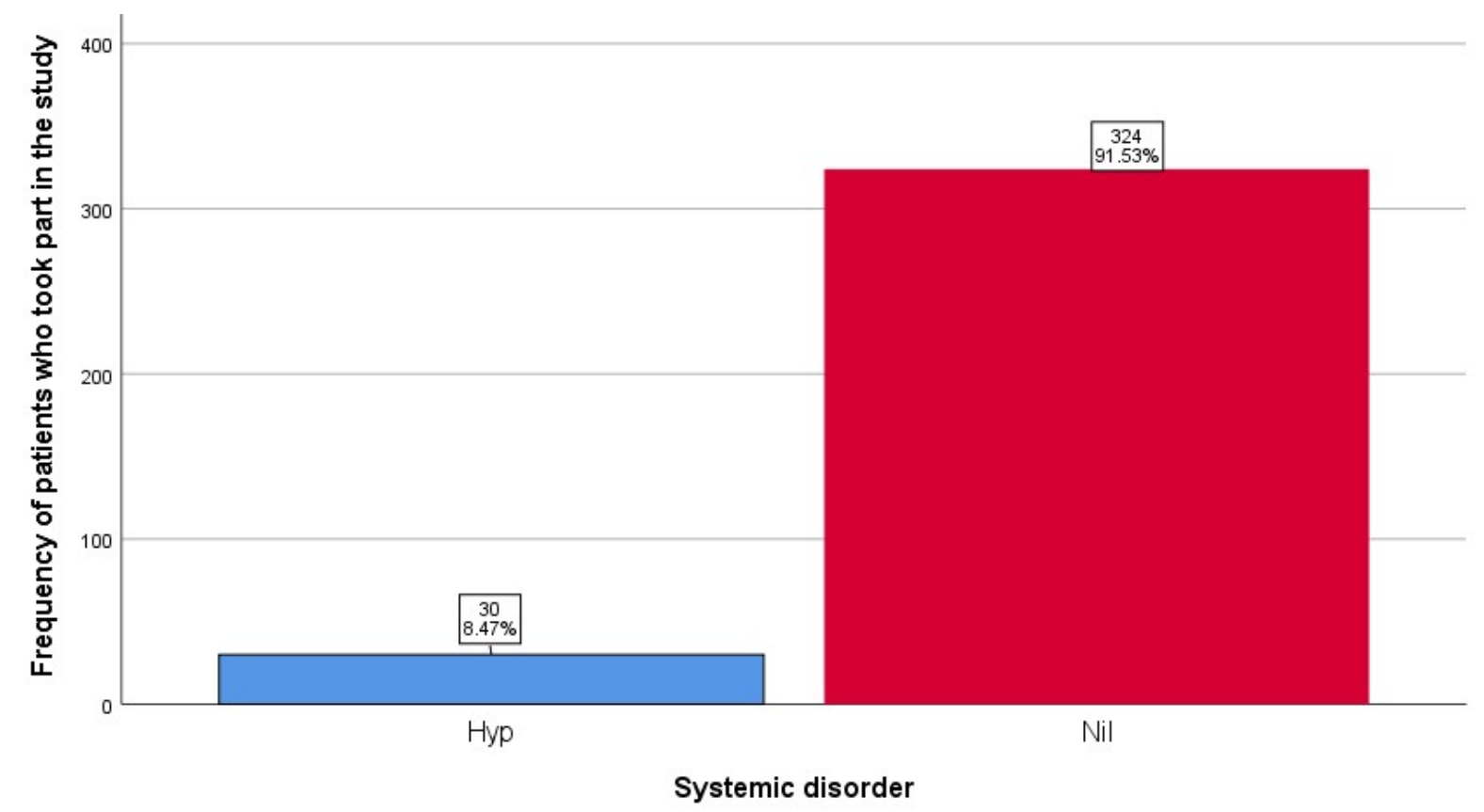

Figure 5: Bar graph depicts the prevalence of hypertension in the overall population. $X$ axis represents the systemic disorder, Y axis represents the frequency of patients. Blue bar represents the patients who had hypertension $8.47 \%(30)$ and the red bar represents the patients who did not have hypertension $91.53 \%$ (324). 


\section{CONCLUSION}

In conclusion, we realized that the prevalence of hypertension among completely edentulous patients visiting our institution was not high and a majority of the people aged 60-75 years were more prevalent with hypertension than the other age groups and males had a slightly higher predilection of hypertension than females who visited. Longitudinal and prospective studies are needed to further elucidate the causal association between edentulism and hypertension

\section{ACKNOWLEDGEMENT}

We would like to thank our statistician for helping us in manuscript preparation.

\section{CONFLICTS OF INTEREST}

There were no conflicts of interest regarding the publication of this article.

\section{REFERENCES}

[1] Kaira LS, Dabral E. Prevalence of complete edentulism among Udaipur population of India [Internet]. Vol. 5, The Saudi Journal for Dental Research. 2014. p. 139-45. Available from: http://dx.doi.org/10.1016/j.ksujds.2013.09.0 02

[2] Southerland JH, Gill DG, Gangula PR, Halpern LR, Cardona CY, Mouton CP. Dental management in patients with hypertension: challenges and solutions. Clin
Cosmet Investig Dent [Internet]. 2016 Oct 17;8:111-20. Available from: http://dx.doi.org/10.2147/CCIDE.S99446

[3] Ajay R, Suma K, Ali S, Sivakumar JK, Rakshagan V, Devaki V, et al. Effect of surface modifications on the retention of cement-retained implant crowns under fatigue loads: An In vitro study [Internet]. Vol. 9, Journal of Pharmacy And Bioallied Sciences. 2017. p. 154. Available from: http://dx.doi.org/10.4103/jpbs.jpbs_146_17

[4] Roy A, Praveen PA, Amarchand R, Ramakrishnan L, Gupta R, Kondal D, et al. Changes in hypertension prevalence, awareness, treatment and control rates over 20 years in National Capital Region of India: results from a repeat cross-sectional study. BMJ Open [Internet]. 2017 Jul 12;7(7):e015639. Available from: http://dx.doi.org/10.1136/bmjopen-2016015639

[5] Danaei G, Finucane MM, Lin JK, Singh GM, Paciorek CJ, Cowan MJ, et al. National, regional, and global trends in systolic blood pressure since 1980: systematic analysis of health examination surveys and epidemiological studies with 786 country-years and 5.4 million participants. Lancet [Internet]. 2011 Feb 12;377(9765):568-77. Available from: http://dx.doi.org/10.1016/S01406736(10)62036-3

[6] Lewington S, Clarke R, Qizilbash N, Peto R, Collins R, Prospective Studies 
Collaboration. Age-specific relevance of usual blood pressure to vascular mortality: a meta-analysis of individual data for one million adults in 61 prospective studies. Lancet [Internet]. 2002 Dec 14;360(9349):1903-13. Available from: http://dx.doi.org/10.1016/s0140-

6736(02)11911-8

[7] Appel LJ, Moore TJ, Obarzanek E, Vollmer WM, Svetkey LP, Sacks FM, et al. A clinical trial of the effects of dietary patterns on blood pressure. DASH Collaborative Research Group. N Engl J Med [Internet]. 1997 Apr 17;336(16):1117-24. Available from:

http://dx.doi.org/10.1056/NEJM199704173 361601

[8] Basha FYS, Ganapathy D, Venugopalan S. Oral Hygiene Status among Pregnant Women [Internet]. Vol. 11, Research Journal of Pharmacy and Technology. 2018. p. 3099. Available from: http://dx.doi.org/10.5958/0974360x.2018.00569.3

[9] Blood pressure, cholesterol, and stroke in eastern Asia [Internet]. Vol. 352, The Lancet. 1998. p. 1801-7. Available from: http://dx.doi.org/10.1016/s0140-

6736(98)03454-0

[10] Antikainen R, Jousilahti P, Tuomilehto J. Systolic blood pressure, isolated systolic hypertension and risk of coronary heart disease, strokes, cardiovascular disease and all-cause mortality in the middle-aged population. J Hypertens [Internet]. 1998 May;16(5):577-83. Available from: http://dx.doi.org/10.1097/00004872199816050-00004

[11] Ni Mhurchu C, Rodgers A, MacMahon S. The associations of diastolic blood pressure with the risk of stroke in Western and Eastern populations. Clin Exp Hypertens [Internet]. 1999 Jul;21(5-6):531-42 . Available from: http://dx.doi.org/10.3109/10641969909060 986

[12] Franklin SS, Larson MG, Khan SA, Wong ND, Leip EP, Kannel WB, et al. Does the relation of blood pressure to coronary heart disease risk change with aging? The Framingham Heart Study. Circulation [Internet]. 2001 Mar 6;103(9):1245-9. Available from: http://dx.doi.org/10.1161/01.cir.103.9.1245

[13] Suggestions for dentists on participating in the National High Blood Pressure Education and Detection Program. Council on Dental Health. J Am Dent Assoc [Internet]. 1977 Jun;94(6):1190. Available from:

http://dx.doi.org/10.14219/jada.archive.197 7.0405

[14] Hypertension detection and control: importance stressed at Dental Leadership Conference on High Blood Pressure. J Am Dent Assoc [Internet]. 1976 Jul;93(1):4850. Available from: http://dx.doi.org/10.14219/jada.archive.197 
6.0585

[15] Popescu SM, Scrieciu M, Mercuţ V, Ţuculina M, Dascălu I. Hypertensive Patients and Their Management in Dentistry. ISRN Hypertension [Internet]. 2013 Dec 9 [cited 2020 Jun 3];2013. Available from: https://www.hindawi.com/journals/isrn/201 3/410740/

[16] Venugopalan S, Ariga P, Aggarwal P, Viswanath A. Magnetically retained silicone facial prosthesis. Niger J Clin Pract [Internet]. $2014 \quad$ Mar;17(2):260-4. Available from: http://dx.doi.org/10.4103/11193077.127575

[17] Kannan A, Venugopalan S. A systematic review on the effect of use of impregnated retraction cords on gingiva [Internet]. Vol. 11, Research Journal of Pharmacy and Technology. 2018. p. 2121. Available from: http://dx.doi.org/10.5958/0974-

360x.2018.00393.1

[18] Courtenay WH. Constructions of masculinity and their influence on men's well-being: a theory of gender and health [Internet]. Vol. 50, Social Science \& Medicine. 2000. p. 1385-401. Available from: http://dx.doi.org/10.1016/s02779536(99)00390-1

[19] Marcell AV, Klein JD, Fischer I, Allan MJ, Kokotailo PK. Male adolescent use of health care services: where are the boys? [Internet]. Vol. 30, Journal of Adolescent
Health. 2002. p. 35-43. Available from: http://dx.doi.org/10.1016/s1054139x(01)00319-6

[20] Ashok V, Nallaswamy D, Benazir Begum S, Nesappan T. Lip Bumper Prosthesis for an Acromegaly Patient: A Clinical Report. J Indian Prosthodont Soc [Internet]. 2014 Dec;14(Suppl 1):279-82. Available from: http://dx.doi.org/10.1007/s13191-013-03396

[21] Miyawaki T, Nishimura F, Kohjitani A, Maeda S, Higuchi $\mathrm{H}$, Kita $\mathrm{F}$, et al. Prevalence of blood pressure levels and hypertension-related diseases in Japanese dental patients. Community Dent Health [Internet]. 2004 Jun;21(2):134-7. Available from:

https://www.ncbi.nlm.nih.gov/pubmed/1522 8201

[22] Ashok V, Suvitha S. Awareness of all ceramic restoration in rural population [Internet]. Vol. 9, Research Journal of Pharmacy and Technology. 2016. p. 1691. Available from: http://dx.doi.org/10.5958/0974360x.2016.00340.1

[23] Pyle MA, Lalumandier JA, Sawyer DR. Prevalence of elevated blood pressure in students attending a college oral health program. Spec Care Dentist [Internet]. 2000 Nov;20(6):234-9. Available from: http://dx.doi.org/10.1111/j.17544505.2000.tb01156.x

[24] Ganapathy DM, Kannan A, Venugopalan S. 
Effect of Coated Surfaces influencing Screw Loosening in Implants: A Systematic Review and Meta-analysis [Internet]. Vol. 8, World Journal of Dentistry. 2017. p. 496-502. Available from: http://dx.doi.org/10.5005/jp-journals10015-1493

[25] Ramaprasad R, Carson PH, Congdon EB, Barta PJ, Ziskin LZ. Dentists and blood pressure measurement: a survey of attitudes and practice. J Am Dent Assoc [Internet]. 1984 May;108(5):767-71. Available from: http://dx.doi.org/10.14219/jada.archive.198 4.0072

[26] Ranganathan H, Ganapathy DM, Jain AR. Cervical and Incisal Marginal Discrepancy in Ceramic Laminate Veneering Materials: A SEM Analysis. Contemp Clin Dent [Internet]. 2017 Apr;8(2):272-8. Available from:

http://dx.doi.org/10.4103/ccd.ccd_156_17

[27] Vijayalakshmi B, Ganapathy D. Medical management of cellulitis [Internet]. Vol. 9, Research Journal of Pharmacy and Technology. 2016. p. 2067. Available from: http://dx.doi.org/10.5958/0974-

360x.2016.00422.4

[28] Ganapathy D, Sathyamoorthy A, Ranganathan H, Murthykumar K. Effect of Resin Bonded Luting Agents Influencing Marginal Discrepancy in All Ceramic Complete Veneer Crowns. J Clin Diagn Res [Internet]. 2016 Dec;10(12):ZC67-70. Available from:
http://dx.doi.org/10.7860/JCDR/2016/2144 7.9028

[29] Subasree S, Murthykumar K, Dhanraj. Effect of Aloe Vera in Oral Health-A Review [Internet]. Vol. 9, Research Journal of Pharmacy and Technology. 2016. p. 609. Available from: http://dx.doi.org/10.5958/0974360x.2016.00116.5

[30] Little JW. The impact on dentistry of recent advances in the management of hypertension. Oral Surg Oral Med Oral Pathol Oral Radiol Endod [Internet]. 2000 Nov;90(5):591-9. Available from: http://dx.doi.org/10.1067/moe.2000.109517

[31] Selvan SR, Ganapathy D. Efficacy of fifth generation cephalosporins against methicillin-resistant Staphylococcus aureusA review [Internet]. Vol. 9, Research Journal of Pharmacy and Technology. 2016. p. 1815. Available from: http://dx.doi.org/10.5958/0974-

360x.2016.00369.3

[32] Ariga P, Nallaswamy D, Jain AR, Ganapathy DM. Determination of Correlation of Width of Maxillary Anterior Teeth using Extraoral and Intraoral Factors in Indian Population: A Systematic Review [Internet]. Vol. 9, World Journal of Dentistry. 2018. p. 68-75. Available from: http://dx.doi.org/10.5005/jp-journals10015-1509

[33] Jyothi S, Robin PK, Ganapathy D, Anandiselvaraj. Periodontal Health Status 
of Three Different Groups Wearing

Temporary Partial Denture [Internet]. Vol.

10, Research Journal of Pharmacy and

Technology. 2017. p. 4339. Available from:

http://dx.doi.org/10.5958/0974-

360x.2017.00795.8

[34] Duraisamy R, Krishnan CS,

Ramasubramanian H, Sampathkumar J,

Mariappan S, Navarasampatti Sivaprakasam

A. Compatibility of Nonoriginal Abutments

With Implants: Evaluation of Microgap at

the Implant-Abutment Interface, With

Original and Nonoriginal Abutments.

Implant Dent [Internet]. 2019

Jun;28(3):289-95. Available from:

http://dx.doi.org/10.1097/ID.000000000000

0885 